\title{
Sympathovagal Imbalance, Decreased Baroreflex Sensitivity and Increased Myocardial Work Stress in Pregnant Women with Risk of Developing Gestational Hypertension: A Preliminary Report
}

\author{
Kuzhanthaivelu Karthiga ${ }^{1}$, Gopal Krushna Pal ${ }^{1, *}$, Subramaniyam Velkumary ${ }^{1}$, Dasari Papa ${ }^{2}$, Chinnakali Palanivel ${ }^{3}$, \\ Nivedita Nanda ${ }^{4}$, Allampalli Sirisha ${ }^{1}$
}

\section{Kuzhanthaivelu Karthiga', Gopal Krushna Pal ${ }^{1, *}$, Subramaniyam Velkumary' , Dasari Papa², Chinnakali Palanivel ${ }^{3}$, Nivedita Nanda ${ }^{4}$, Allampalli Sirisha ${ }^{1}$}

'Department of Physiology, Jawaharlal Institute of Post-graduate Medical Education and Research, Puducherry, INDIA.

${ }^{2}$ Obstetrics and Gynaecology, Jawaharlal Institute of Post-graduate Medical Education and Research, Puducherry, INDIA.

${ }^{3}$ Preventive and Social Medicine, Jawaharlal Institute of Post-graduate Medical Education and Research, Puducherry, INDIA.

${ }^{4}$ Department of Biochemistry, Jawaharlal Institute of Post-graduate Medical Education and Research, Puducherry, INDIA.

\section{Correspondence}

\section{Dr. Gopal Krushna Pal}

Senior Professor, Department of Physiology, Jawaharlal Institute of Post-graduate Medical Education and Research, Puducherry-605 006, INDIA.

Email: drgkpal@gmail.com

\section{History}

- Submission Date: 05-05-2019;

- Review completed: 26-06-2019;

- Accepted Date: 30-06-2019.

DOI : 10.5530/ijcep.2019.6.2.18

\section{Copyright}

(C) 2019 Phcog.Net. This is an openaccess article distributed under the terms of the Creative Commons Attribution 4.0 International license.

\begin{abstract}
Background and Aim: Though the mechanisms responsible for the pathogenesis of Gestational Hypertension (GHT) are unclear, it has been reported that the disease is characterized by low circulating volume and high vascular resistance. The increased peripheral vascular resistance is caused due to sympathetic overactivity which in turn causes the increase in blood pressure and Cardiovascular risk (CV). Therefore, in the present study, we aimed to study the sympathovagal imbalance, Baroreflex Sensitivity (BRS) and Rate Pressured Product (RPP) in pregnant women with risk of developing GHT during their first and third trimesters of gestation. Methods: Heart Rate (HR), Systolic and Diastolic Blood Pressure (SBP, DBP) were measured. Rate-pressure product was calculated using SBP and HR. Spectral analysis of Heart Rate Variability (HRV), Blood Pressure Variability (BPV) including BRS were assessed in a group of pregnant women $(n=18)$ with risk factors for GHT at $16^{\text {th }}$ week and 36th week of their gestation. Parameters were compared after $36^{\text {th }}$ week with 16 th weeks and analyzed. Results: It was observed that the ratio of low-frequency to high-frequency power (LF-HF ratio) of HRV was significantly increased at $36^{\text {th }}$ week of pregnancy compared with $16^{\text {th }}$ week. There was decreased BRS at $36^{\text {th }}$ week of pregnancy in risk of GHT. Significant increase in RPP was seen at $36^{\text {th }}$ week of pregnant women with risk of developing GHT when compared with $16^{\text {th }}$ of gestation. Conclusion: In the present study we conclude that there is sympathovagal imbalance in pregnant women with risk of developing GHT. Also reduced $B R S$ and increased RPP were seen in these subjects indicating that there was increased $\mathrm{CV}$ risk in these patients.

Key words: Baroreflex sensitivity, Gestational hypertension, Myocardial work stress, Cardiovascular risks, Sympathovagal imbalance.
\end{abstract}

\section{INTRODUCTION}

Hypertension is one of the most common medical problem encountered in $15 \%$ of pregnancies and it contributes to $12 \%$ of maternal mortality especially in developing countries of south-east Asia. ${ }^{[1,2]}$ The International Society for the Study of Hypertension in Pregnancy has defined Gestational Hypertension (GHT) as the level of Blood Pressure (BP) of at least $140 / 90 \mathrm{mmHg}$ on two separate occasions, more than $4 \mathrm{hr}$ apart, arising de novo after the $20^{\text {th }}$ week of gestation in a previously normotensive woman. ${ }^{[3]}$ GHT is one of the major complication of pregnancy that contributes significantly to still births and neonatal and maternal morbidity and mortality, especially in developing countries. ${ }^{[4]}$

Sympathovagal Imbalance (SVI) has been documented to be associated with $\mathrm{CV}$ morbidities in different clinical conditions. ${ }^{[5,6]}$ Spectral analysis of Heart Rate Variability (HRV) has been documented as a tool for assessment of autonomic imbalance in health and diseases. ${ }^{[7]}$ Even though, the mechanisms responsible for the pathogenesis of GHT are unclear, There are reports stating that increased vascular resistance in GHT is due to the increased sympathetic tone ${ }^{[8,9]}$ Earlier we have reported that there is sympathovagal imbalance in hypertension. ${ }^{[10]}$

Recently, it has been reported that Baroreceptor Reflex Sensitivity (BRS) assessed by continuous Blood Pressure Variability (BPV) monitoring was sensitive measure and a marker of cardiovascular risk, along with increased Rate Pressure Product (RPP) was also explains the myocardial work stress. ${ }^{[11-15]}$ However, BRS and RPP were not assessed in GHT, Hence, in the present study we have assessed sympathovagal imbalance, BRS and RPP in pregnant women with risk of developing GHT.

\section{MATERIALS AND METHODS}

The present study was conducted in the Department of Physiology, Jawaharlal Institute of Postgraduate
Cite this article: Karthiga K, Pal GK, Velkumary S, Papa D, Palanivel C, Nanda N, et al. Sympathovagal Imbalance, Decreased Baroreflex Sensitivity and Increased Myocardial Work Stress in Pregnant Women with Risk of Developing Gestational Hypertension: A Preliminary Report. Int J Clin Exp Physiol. 2019;6(2):71-4. 
Medical Education and Research (JIPMER), Pondicherry, India. After obtaining approval from research and ethics committees of JIPMER, 18 subjects were recruited from the out - patient unit of the Obstetrics and Gynaecology department of JIPMER. Written and informed consent was obtained from all the participants prior to initiation of the study. Pregnant women who had none of the risk factors for PIH like family history of preeclampsia, preeclampsia in previous pregnancy, extremes of reproductive age, body mass index $(\mathrm{BMI})>35$, diastolic blood pressure (DBP) $>80 \mathrm{mmHg}$ at the first visit, first pregnancy, multiple pregnancy, underlying medical conditions (diabetes mellitus, renal disease, pre-existing hypertension), were included in the study.

Subjects attend Obstetrics OPD for their regular check-ups and also reported to Autonomic Function Testing (AFT) laboratory of Physiology department for recording of various parameters at $16^{\text {th }}$ week and $36^{\text {th }}$ week of pregnancy. The subjects reported to laboratory about two hours after a light breakfast devoid of coffee or tea. Height and weight were measured to calculate Body Mass Index (BMI). Blood Pressure (BP) was recorded using the automatic non-invasive BP monitor, (Omron, HEM 7203 model, Omron Healthcare Co., Kyoto, Japan). Heart rate, systolic BP and DBP were noted from the display screen of BP monitor, Mean Arterial Pressure (MAP) and Rate Pressure Product (RPP) was calculated using SBP and HR. ${ }^{[16]}$

HRV recording Following $10 \mathrm{~min}$ of supine rest in AFT laboratory (room temperature maintained at $25^{\circ} \mathrm{C}$ ), basal heart rate (BHR) and BP (diastolic and systolic) were recorded. For recording of short-term HRV, recommendation of the Task Force on HRV was followed. ${ }^{[17]}$ For this purpose, Lead II ECG electrodes were connected and acquired at a rate of 1000 samples/second during supine rest using BIOPAC MP 100 data acquisition system (BIOPAC Inc., USA). The data was transferred from BIOPAC to a windows-based PC with AcqKnowledge software version 3.8.2. Ectopics and artefacts were removed from the recorded ECG. RR tachogram was extracted from the edited $256^{-}$s ECG using the R wave detector in the AcqKnowledge software and saved in ASC-II format, which was later used offline for short term HRV analysis. HRV analysis was done using the HRV analysis software version 1.1 (Bio-signal Analysis group, Finland). Among the frequency-domain indices of $\mathrm{HRV}$, ratio of low-frequency to high-frequency power (LF-HF ratio) was recorded.

\section{Recording of BRS}

BRS was measured by continuous BPV method using Finapres (Finometer version 1.22a, Finapres Medical Systems, Amsterdam, The Netherlands); a non-invasive continuous hemodynamic CV monitor based on the principle of measurement of finger arterial pressure with the volume clamp technique of Penaz and the Physical criteria of Wesseling. ${ }^{[18]}$ In this method, the brachial artery pressure measured was the reconstructed pressure from the finger pressure, estimated through generalized waveform inverse modeling and generalized level correction. The subjects were asked to lie down and the brachial cuff of finapres was tied around the mid-arm about $2 \mathrm{~cm}$ above the cubital fossa and the finger cuff of small, medium or large size were tied around the middle phalanx of the middle finger depending on the finger width. For the height correction, two sensors were placed, one at the heart level and another at the finger level. The recordings were obtained following connection of cables of the cuffs to the Finometer, after ten minutes of supine rest. The "return to flow calibration and the physical" was done for the level correction between the brachial and finger pressure during the initial 5 min of the recordings. Following this, the continuous Blood Pressure (BP) recording was done for a period of $10 \mathrm{~min}$. The reconstructed brachial pressure was acquired through a PC based data acquisition system (Finapres Medical Systems BV, Amsterdam, The Netherlands). The parameters recorded from the reconstructed brachial pressure tachogram interbeat interval, Left Ventricular Ejection Time (LVET), stroke volume (SV), cardiac output, Total Peripheral Resistance (TPR) and BRS along with basal CV parameters.

\section{Statistical Analysis of Data}

SPSS, version 13 (SPSS Software Inc., Chicago, Illinois) was used for statistical analysis. All the data are expressed as mean \pm SD. Normality of data was tested by Kolmogorov-Smirnov test. For parametric data, the level of significance between the groups was tested by Student paired $t$ test and for nonparametric data, Welch's corrected t test was used. A $p$ value $<0.05$ was considered statistically significant.

\section{RESULTS}

There was a significant increase in the body weight in these subjects. The systolic and diastolic BP was significantly increase at $36^{\text {th }}$ week when compared with $16^{\text {th }}$ week of pregnancy. There was significant increase in MAP and RPP at $36^{\text {th }}$ week when compared to $16^{\text {th }}$ week of pregnant women with risk of developing GHT [Table 1].

There was reduction in SDNN, RMSSD, NN50 and pNN50 at $36^{\text {th }}$ week when compared to $16^{\text {th }}$ of pregnancy [Table 2]. There was significant reduction in very low frequency and Total Power at $36^{\text {th }}$ week when compared with $16^{\text {th }}$ week of pregnancy. Increased LF power was seen at $36^{\text {th }}$ week when compared with $16^{\text {th }}$ week. Among the frequency-domain indices, LF/HF ratio was significantly increased at $36^{\text {th }}$ week compared with $16^{\text {th }}$ week [Table 2].

Blood pressure variability parameters show increased SV, LVET and CO at $36^{\text {th }}$ week when compared to $16^{\text {th }}$ week. There was significant increase in total peripheral resistance at $36^{\text {th }}$ week compared with $16^{\text {th }}$ week of pregnancy. There was reduction in BRS at $36^{\text {th }}$ week when compared with $16^{\text {th }}$ week of pregnant women with risk of developing GHT [Table 3].

\section{DISCUSSION}

The significant increase in Systolic and diastolic BP which suggest that subjects having risks of developing GHT have altered CV parameters even in the early part of pregnancy which is continued to increase in the later part of pregnancy. The level of BP is the function of vascular

\section{Table 1: Comparison of body weight, heart rate, blood pressure and rate pressure product of pregnant women at risk of developing gesta- tional hypertension at 16 weeks and 36 weeks.}

$\begin{array}{cccc}\text { Parameters } & \begin{array}{c}\text { Pregnant } \\ \text { women } \\ \text { At risk of GHT }\end{array} & \begin{array}{c}\text { Pregnant } \\ \text { women } \\ \text { At risk of GHT }\end{array} & \text { P value } \\ & \begin{array}{c}\text { At 16 weeks } \\ (\boldsymbol{n}=\mathbf{1 8})\end{array} & \begin{array}{c}\text { At 36 weeks } \\ (\boldsymbol{n}=\mathbf{1 8})\end{array} & \\ & 51.93 \pm 9.37 & 60.32 \pm 9.49 & 0.0116 \\ \text { Body weight }(\mathrm{kg}) & 86.88 \pm 10.63 & 90.39 \pm 6.39 & 0.2382 \\ \text { BHR (bpm) } & 110.07 \pm 9.86 & 129.75 \pm 14.83 & <0.0001 \\ \text { SBP (mmHg) } & 67.90 \pm 6.92 & 84.93 \pm 7.22 & <0.0001 \\ \text { DBP (mmHg) } & 85.90 \pm 8.15 & 114.81 \pm 11.21 & <0.0001 \\ \text { MAP (mmHg) } & 95.36 \pm 11.45 & 117.22 \pm 14.38 & <0.0001 \\ \text { RPP (mmHg) } & \end{array}$

The data presented are Mean \pm SD. $P$ value $<0.05$ was considered as statistically significant. BHR - Basal heart rate, SBP - Systolic blood pressure, DBP - Diastolic blood pressure, MAP - Mean arterial pressure, RPP - Rate pressure product 
Table 2: Comparison of heart rate variability of pregnant women at risk of developing gestational hypertension at 16 weeks and 36 weeks.

\begin{tabular}{|c|c|c|c|}
\hline Parameters & Pregnant women & $\begin{array}{l}\text { Pregnant } \\
\text { women }\end{array}$ & $P$ value \\
\hline & $\begin{array}{l}\text { At risk of GHT } \\
\text { At } 16 \text { weeks } \\
\quad(n=18)\end{array}$ & $\begin{array}{l}\text { At risk of GHT } \\
\text { At } 36 \text { weeks } \\
\quad(n=18)\end{array}$ & \\
\hline \multicolumn{4}{|c|}{ Frequency domain } \\
\hline \multicolumn{4}{|l|}{ Indices of HRV } \\
\hline $\mathrm{TP}\left(\mathrm{ms}^{2}\right)$ & $1124.77 \pm 230.25$ & $898.11 \pm 193.34$ & 0.0016 \\
\hline VLF (Hz) & $489.33 \pm 112.45$ & $312.33 \pm 88.23$ & $<0.0001$ \\
\hline $\mathrm{LF}(\mathrm{Hz})$ & $288.5 \pm 87.95$ & $344.66 \pm 88.23$ & 0.0643 \\
\hline $\mathrm{HF}(\mathrm{Hz})$ & $344.55 \pm 98.48$ & $278.88 \pm 358.88$ & 0.4592 \\
\hline $\mathrm{LF}(\mathrm{nu})$ & $53.1 \pm 15.99$ & $59.8 \pm 22.47$ & 0.3100 \\
\hline HF (nu) & $46.41 \pm 16.41$ & $41.30 \pm 14.72$ & 0.3323 \\
\hline LF/HF ratio & $1.14 \pm 0.50$ & $1.62 \pm 0.67$ & $<0.0001$ \\
\hline \multicolumn{4}{|l|}{ Time domain } \\
\hline \multicolumn{4}{|l|}{ Indices of HRV } \\
\hline SDNN (ms) & $37.32 \pm 16.42$ & $32.42 \pm 12.41$ & 0.3196 \\
\hline RMSSD (ms) & $34.48 \pm 15.26$ & $30.91 \pm 10.25$ & 0.4157 \\
\hline NN50 (beats) & $36.72 \pm 60.31$ & $29.72 \pm 13.67$ & 0.6341 \\
\hline pNN50 (\%) & $8.31 \pm 14.79$ & $7.23 \pm 3.52$ & 0.7650 \\
\hline
\end{tabular}

The data presented are Mean \pm SD. $P$ value $<0.05$ was considered as statistically significant.TP- Total power, VLF- Very low frequency, LF- Low frequency, HFHigh frequency, SDNN- Standard deviation of NN, RMSSD- Square root of the mean of the sum of the squares of the differences between adjacent NN intervals, NN50- Number of interval differences of successive $\mathrm{NN}$ interval greater than 50 , pNN50- Proportion derived by dividing NN50 by the total number of $\mathrm{NN}$ intervals.

Table 3: Comparison of blood pressure variability of pregnant women at risk of developing gestational hypertension at 16 weeks and 36 weeks.

$\begin{array}{cccc}\text { Parameters } & \begin{array}{c}\text { Pregnant } \\ \text { women } \\ \text { At risk of GHT } \\ \text { At 16 weeks } \\ (\boldsymbol{n}=\mathbf{1 8})\end{array} & \begin{array}{c}\text { Pregnant } \\ \text { women } \\ \text { At risk of GHT } \\ \text { At 36 weeks } \\ (\boldsymbol{n}=\mathbf{1 8})\end{array} & \text { P value } \\ \text { SV (mL) } & 62.31 \pm 11.71 & 62.23 \pm 12.85 & 0.4810 \\ \text { LVET (ms) } & 309.70 \pm 28.06 & 317.12 \pm 19.35 & 0.3622 \\ \text { CO (L/min) } & 5.36 \pm 0.90 & 5.55 \pm 0.86 & 0.5216 \\ \text { TPR (mmHg. } & 0.99 \pm 0.24 & 1.15 \pm 0.12 & 0.0162 \\ \text { min/L) } & & & \\ \text { BRS (ms/mmHg) } & 13.79 \pm 5.50 & 11.17 \pm 3.01 & 0.0852\end{array}$

The data presented are Mean \pm SD. $P$ value $<0.05$ was considered as statistically significant. SV- Stroke volume, LVET- Left ventricular ejection time, CO- Cardiac Output, TPR- Total peripheral resistance, BRS- Baroreflex sensitivity

resistance that reflects the sympathetic tone. ${ }^{[19]}$ Thus, the increase BP at $36^{\text {th }}$ week when compared to $16^{\text {th }}$ week of gestation indicates increased sympathetic tone in pregnant women with GHT. Heart Rate (HR) at rest is the function of vagal tone and increase in HR represents decreased va- gal activity. ${ }^{[17]}$ Though not significant there is increased HR in these subjects indicating decreased vagal tone in them. The increase sympathetic activity and decreased vagal tone causes sympathovagal imbalance in pregnant women with risk of developing GHT. TP in general represents the parasympathetic potency of cardiac modulation. ${ }^{[5]}$ The reduction in TP along with VLF in these subjects represents the decreased parasympathetic activity.

LF-HF ratio is the index of SVI and increase in this ratio reflects increased sympathetic activity. ${ }^{[7]}$ In the present study significant increase in $\mathrm{LF}-\mathrm{HF}$ ratio at $36^{\text {th }}$ week when compared to $16^{\text {th }}$ week, indicates the sympathetic overactivity in subjects with GHT. There was a reduction in RPP at $36^{\text {th }}$ week when compared to $16^{\text {th }}$ week. RPP is a measure of myocardial work load and oxygen utilization. Increased RPP, especially in individuals with high $\mathrm{BP}$ has been reported as a potential $\mathrm{CV}$ risk. ${ }^{[15]}$ Though in the clinical setting, the measurement of myocardial oxygen consumption is by indirect invasive method and quite difficult to measure, the RPP acts as an indirect and easy method of measuring the myocardial oxygen consumption. ${ }^{[20,21]}$ Increased RPP in pregnant women at risk for GHT indicates that there is increased myocardial work stress in these pregnant women and they are at risk of developing cardiovascular disease in future.

TPR, an indicator of sympathetic vasoconstrictor tone has been suggested as a predictor of CV disease risk. ${ }^{[22]}$ Arterial baroreceptors play a central role in BP regulation in response to various stimuli through alteration in both sympathetic and vagal activities and therefore assessment of BRS provides the state of SVI in various CV disease states. ${ }^{[14]}$ Hypertension, which is the cardinal symptom of preeclampsia, is usually accompanied by diminished BRS. ${ }^{[23]}$ In the present study, BRS was reduced at $36^{\text {th }}$ week when compared to $16^{\text {th }}$ week in subjects who are having risk of developing GHT, which indicates there is a CV risks in these subjects. Future studies should be conducted in these women to see the effect of change in life style modifications or adjunct therapies to reduce the $\mathrm{CV}$ risk and myocardial work stress in them.

From the present study, it can't be definitely ascertained that the sympathovagal imbalance (alteration in LF-HF ratio) in women with risk factors for GHT is directly linked to CV risks such as increased RPP and decreased BRS, as correlation and regression could not be done to establish these associations due to less sample size. However, it appears that sympathovagal imbalance has a greater influence on the blood pressure derived parameters such as RPP and BRS, as in our previous studies we have reported similar association in general hypertensive patients. ${ }^{[10]}$

\section{CONCLUSION}

In the present study we conclude that there is sympathovagal imbalance in pregnant women with risk of developing GHT. Also, reduced BRS and increased RPP seen in these subjects indicating the increased CV risk in these patients.

\section{Limitations of the Study}

Since the sample size was less we couldn't perform the correlation and regression tests. Because of the less sample size baroreflex sensitivity doesn't shows much significance.

\section{ACKNOWLEDGEMENT}

The authors acknowledge the financial assistance for Ph.D programme for the first author from JIPMER through the intramural fund granted.

\section{CONFLICT OF INTEREST}

The authors declare no conflict of interest. 


\section{REFERENCES}

1. James PR, Nelson-Piercy C. Management of hypertension before, during and after pregnancy. Heart. 2004;90(12):1499-504

2. Pal P, Pal G, Sridhar M, Subha M, Syed H, Adithan $C$. Association of sympathovagal imbalance with arterial stiffness indices in women with risk factors for pregnancy-induced hypertension in first and third trimesters of gestation. Int $J$ Clin Exp Physiol. 2014;1(2):113-9.

3. Sibai B. Diagnosis and Management of Gestational Hypertension and Preeclampsia. Obstet Gynecol. 2003;102(1):181-92

4. Ananth CV, Basso O. Impact of Pregnancy-Induced Hypertension on Stillbirth and Neonatal Mortality in First and Higher Order Births: A Population-Based Study. Epidemiology. 2010;21(1):118-23.

5. Pal GK, Shyma P, Habeebullah S, Pal P, Nanda N, Shyjus P. Vagal Withdrawal and Sympathetic Overactivity Contribute to the Genesis of Early-Onset PregnancyInduced Hypertension. Int J Hypertens. 2011;2011:1-9.

6. Hans PS, Thorsten F, Karsten H, Helmut G, Ronal ES. Preeclampsia: A state of sympathetic overactivity. New Eng J Med. 1996;335(20):1480-5.

7. Malliani A. Heart rate variability: from bench to bedside. Eur J Intern Med. 2005;16(1):12-20

8. Greenwood JP, Stoker JB, Walker JJ, Mary DA. Sympathetic nerve discharge in normal pregnancy and pregnancy-induced hypertension. J Hypertens 1998:16(5):617-24.

9. Thayer JF, Yamamoto SS, Brosschot JF. The relationship of autonomic imbalance, heart rate variability and cardiovascular disease risk factors. Int J Cardiol. 2010;141(2):122-31.

10. Pal GK, Pal P, Nanda N, Amudharaj D, Adithan C. Cardiovascular dysfunctions and sympathovagal imbalance in hypertension and prehypertension: Physiological perspectives. Future Cardiology. 2012;9(1):53-69

11. Pellizzer AM, Kamen PW, Jackman G, Brazzale D, Krum H. Non-invasive assessment of baroreflex sensitivity and relation to measures of heart rate variability in man. Clin Exp Pharmacol Physiol. 1996;23(6-7):621-4. Jansen JR, Schreuder JJ, Mulier JP, Smith NT, Settels JJ, Wesseling KH. A comparison of cardiac output derived from the arterial pressure wave against thermodilution in car- diac surgery patients. Br J Anaesth. 2001;87(2):212-22. Rovere MTL, Pinna GD, Raczak G. Barorefl ex sensitivity: measurement and clinical implications. Ann Noninvasive Electrocardiol. 2008;13(2):191-207.Rovere MT, Maestri R, Pinna GD. Barorefl ex sensitivity assessment: Latest advances and strategies. Eur Cardiol. 2011;7(2):89-92

12. White WB. Heart rate and the rate-pressure product as determinants of car diovascular risk in patients with hypertension. Am J Hypertens. 1999;12(2 Pt 2):50S-5S.

13. Electrophysiology TF. Heart rate variability: Standard and measurement, physiological interpretation and clinical use: Task force of the European Society of Cardiology and the North American society of Pacing and Electrophysiology. Circulation. 1996;93(5):1043-65.

14. Pal GK, Pal P. Autonomic function tests. In: Textbook of Practical Physiology. $3^{\text {rd }}$ ed. Chennai: Universities Press. 2010;282-90.

15. Imholz BP, Wieling W, Montfrans GAV, Wesseling KH. Fifteen year's experience with finger arterial pressure monitoring: Assessment of the technology. Cardiovasc Res. 1998;38(3):605-16.

16. Ganong WF. Cardiovascular regulatory mechanisms. In: Review of Medical Physiology. 22 ${ }^{\text {nd }}$ ed. San Fransisco: McGraw Hill. 2005;597-602.

17. Nagpal S, Walia L, Lata H, Sood N, Ahuja GK. Effect of exercise on rate pressure product in premenopausal and postmenopausal women with coronary artery disease. Indian J Physiol Pharmacol. 2007;51(3):279-83. Kal JE, Wezel HBV, Vergroesen I. A critical appraisal of the rate pressure product as index of myocardial oxygen consumption for the study of metabolic coronary flow regulation. Int J Cardiol. 1999;71(2):141-8.

18. Feldt K, Räikkönen K, Pyhälä R, Jones A, Phillips DI, Eriksson JG, et al. Body size at birth and cardiovascular response to and recovery from mental stress in children. J Hum Hypertens. 2011;25(4):231-40.

19. Parmer RJ, Hustine H, Cervenka RT, Stone RA. Baroreflex sensitivity and heredity in essential hypertension. Circulation. 1992;85(2):497-503.

Cite this article: Karthiga K, Pal GK, Velkumary S, Papa D, Palanivel C, Nanda N, et al. Sympathovagal Imbalance, Decreased Baroreflex Sensitivity and Increased Myocardial Work Stress in Pregnant Women with Risk of Developing Gestational Hypertension: A Preliminary Report. Int J Clin Exp Physiol. 2019;6(2):71-4. 